\title{
SAINDO DA TRINCHEIRA DO \\ DESENVOLVIMENTO SUSTENTÁVEL: UMA \\ NOVA PERSPECTIVA PARA A ANÁLISE E A DECISÃO EM SUSTENTABILIDADE
}

\author{
DIEGO ANTONIO BITTENCOURT MARCONATTO \\ Doutorando em Administração pelo Departamento de Ciências Administrativas da \\ Universidade Federal do Rio Grande do Sul (UFRGS). \\ Rua Washington Luiz, 855, Centro, Porto Alegre - RS - Brasil - CEP 90010-460 \\ E-mail:dmarconatto@gmail.com
}

MARCELO TREVISAN

Mestre em Administração pelo Departamento de Ciências Administrativas da Universidade Federal de Santa Catarina (UFSC).

Professor do Departamento de Ciências Administrativas da Universidade Federal de Santa Maria (UFSM). Avenida Roraima, 1.000/74C, sala 4.123, Comobi, Santa Maria - RS - Brasil - CEP 97015-372

E-mail: marcelotrevisan@smail.ufsm.br

EUGENIO AVILA PEDROZO

Doutor em Gestão pelo Departamento Génie Des Systèmes Industriels do Institut National Polytechnique de Lorraine (INPL) - Nancy Université.

Professor do Departamento de Ciências Administrativas da Universidade Federal do Rio Grande do Sul (UFRGS). Rua Washington Luis, 855, sala 412, Centro, Porto Alegre - RS - Brasil - CEP 90010-460

E-mail: eapedrozo@ea.ufrgs.br

\section{KLEITON DOUGLAS SAGGIN}

Mestre em Agronegócios pelo Centro de Estudos e Pesquisas em Agronegócios da Universidade Federal do Rio Grande do Sul (Cepan-UFRGS).

Fiscal estadual agropecuário da Secretaria Estadual da Agricultura do Rio Grande do Sul. Avenida Getúlio Vargas, 1.384, Menino Deus, Porto Alegre - RS - Brasil - CEP 90150-004 E-mail: kleiton-saggin@agricultura.rs.gov.br

\section{VALDECIR JOSÉ ZONIN}

Doutorando em Agronegócios do Centro de Estudos e Pesquisas em Agronegócios da Universidade Federal do Rio Grande do Sul (Cepan-UFRGS). Avenida Bento Gonçalvez, 7.712, Agronomia, Porto Alegre - RS - Brasil - CEP 91540-000 E-mail:valdecirzonin@terra.com.br

Este artigo pode ser copiado, distribuído, exibido, transmitido ou adaptado desde que citados, de forma clara e explícita, o nome da revista, a edição, o ano, e as páginas nas quais o artigo foi publicado originalmente, mas sem sugerir que a RAM endosse a reutilização do artigo. Esse termo de licenciamento deve ser explicitado para os casos de reutilização ou distribuição para terceiros. Não é permitido o uso para fins comerciais. 


\section{RESUMO}

O desenvolvimento sustentável está entrincheirado. Seu campo é marcado por visões e interesses conflitantes que retroalimentam a fragmentação da temática em dois principais grupos ideológicos que se opõem. Em uma trincheira, estão os biocentrados que advogam pela priorização da preservação dos recursos naturais sobre os sistemas socioeconômicos; a outra trincheira é ocupada pelos antropocentrados, movidos pelas crenças de que a natureza existe para servir ao homem e de que o crescimento dos mercados e o incremento tecnológico são suficientes para garantir a sustentabilidade. Essa contraposição dificulta a construção de uma visão conjunta para o desenvolvimento sustentável, o que resulta no avanço lento, quando não no retrocesso da busca por um maior equilíbrio entre economia, sociedade e meio ambiente, ao redor do mundo. Há então a necessidade de diminuir a distância entre ambas as posições, de forma que haja espaço para a construção de ações e políticas de um desenvolvimento sustentável realmente viável. O objetivo deste ensaio é propor uma nova perspectiva conceitual de análise e decisão sustentáveis, que permita uma maior aproximação dessas duas visões. A partir de um "mapa geral", que localiza biocentrados e antropocentrados em campos opostos, inicia-se a construção de uma proposição de modelo conceitual analítico-decisório voltado para o problema. A perspectiva da ecologia industrial é integrada à teoria dos stakeholders e à sustentabilidade 3-D de Mauerhofer (2008), para a construção dessa proposição, concebida de forma a refletir características intrínsecas do desenvolvimento sustentável e funcionar como um circuito fechado, retroalimentado. O modelo proposto atende ao objetivo deste ensaio e é sua principal contribuição. Sugerem-se como estudos futuros: I. o desenvolvimento operacional e a posterior aplicação desse modelo sobre os principais argumentos de biocentrados e antropocentrados, presentes nos diversos foros de discussão; e 2. a adaptação do modelo a indústrias específicas. 


\section{PALAVRAS-CHAVE}

Desenvolvimento sustentável; Modelo analítico-decisório; Biocentrado; Antropocentrado; Ecologia industrial.

\section{INTRODUÇÃO}

A teoria e a prática do desenvolvimento sustentável estão entrincheiradas. A emergência do assunto, facilmente verificável nas diversas mídias, no âmbito acadêmico, no cotidiano empresarial e nas pautas governamentais, de modo algum, sugere que há substancial consenso a respeito do assunto. Ao contrário, dadas as suas características complexas (DETOMBE, 2008), o desenvolvimento sustentável caracteriza-se fortemente pelas pluralidades de perspectivas e é marcado por inúmeros conflitos de opinião, visão e interesse (HOPWOOD; MELLOR; O'BRIEN, 2005), que parecem retroalimentar a fragmentação da temática em grupos ideológicos e de pressão, organizados de diferentes modos e, por vezes, posicionados cada qual em uma trincheira.

Em I992, os conceitos de desenvolvimento sustentável eram contados em mais de uma centena (HOLMBERG; SANDBROOK, I992). As diferentes conceituações reafirmam, corroboram, questionam ou contrapõem o famoso conceito de Brundtland ${ }^{\mathrm{I}}$, de I987. Alguns autores colocam em dúvida a sua validade, criticando-o por representar interesses puramente econômicos - à custa das dimensões social e ambiental -, especialmente os dos países mais ricos (BANERJEE, 2003; KORTEN, I996); outros o entenderam como sendo excessivamente antropocentrista, calcado exclusivamente sobre a crença na tecnologia e no livre mercado como via de solução absoluta para as várias problemáticas, inerentes à construção de um desenvolvimento realmente sustentável (ROBINSON, 2004). Essas divergências acumulam-se umas sobre as outras e podem ser citadas às dezenas. Produto disso é a polarização de grupos de ação e opinião em campos opostos, entrincheirados em crenças contrárias. Ambos sustentam-se sobre ideologias e propostas de solução que não raro ignoram-se ou mesmo se excluem mutuamente. Nesse caldeirão, encontram-se governos, corporações, instituições acadêmicas, ONGs, movimentos civis, órgãos supranacionais, movimentos religiosos, entre outros (MEBRATU, I998). Como resultado, tem-se o avanço lento, quando

\footnotetext{
"A humanidade deve ter a habilidade de trilhar o desenvolvimento sustentável - garantir que as necessidades do presente sejam atendidas sem comprometer a habilidade das futuras gerações de atender às suas próprias necessidades" (World Commission on Environment and Development, 1987, p. 43).
} 
não o retrocesso do desenvolvimento sustentável ao redor do mundo: embora haja regiões globais que atingiram patamares interessantes em termos de sustentabilidade, o quadro geral que persiste é o de forte desequilíbrio econômico, social e ambiental (IPCC, 2007).

Portanto, é evidentemente necessário um maior aprofundamento no debate sobre o desenvolvimento sustentável, acompanhado de um esforço conciliatório, no sentido não de eliminar de uma vez por todas as contradições teóricas e práticas que o marcam, mas de oferecer às suas diferentes perspectivas uma maior possibilidade de coexistência e convergência. É este o objetivo central deste ensaio: propor um modelo conceitual, de suporte às analises e às decisões gerenciais, de modo a permitir uma maior aproximação de visões de sustentabilidade que sejam profundamente diferentes.

Para tal, inicialmente será mostrado, por meio da revisão de literatura, como as principais concepções de desenvolvimento sustentável estão organizadas em duas trincheiras opostas, fundadas sobre lógicas e objetivos claramente diferentes: de um lado estão os biocentrados, militantes dos direitos e da superioridade da natureza; e, do outro, os antropocentrados, organizados em torno da ideia de que a natureza existe para servir ao homem. Posteriormente, será iniciada a construção do modelo conceitual, de suporte às análises e às decisões gerenciais que potencialmente influenciem a sustentabilidade. Essa construção utiliza-se da articulação das teorias da ecologia industrial (EI), dos stakeholders e do modelo 3-D de sustentabilidade de Mauerhofer (2008). O quarto tópico apresenta o modelo conceitual finalizado e o seu funcionamento, para então serem apresentadas as considerações finais deste trabalho.

\section{AS GRANDES TRINCHEIRAS DO DESENVOLVIMENTO SUSTENTÁVEL}

Segundo Pearce, Barbier e Markandya (1989), um dos pontos mais marcantes nos vários conceitos de desenvolvimento sustentável está na perspectiva adotada quanto à relação do homem (e seus sistemas técnicos, econômicos e sociais) com a natureza. Como é possível observar nas discussões que seguem, a primazia do homem sobre a natureza (visão antropocêntrica) ou da natureza sobre o homem (visão biocêntrica) tende a gerar visões polarizadas de mundo embora dispostas em um mesmo continuum. Essa aparente dicotomia implica desdobramentos diversos, dispostos de forma contrária e refletidos em modos opostos de pensar o desenvolvimento sustentável, em termos de preferências metodológicas, políticas, filosóficas ou científicas. Portanto, é importante apro- 
fundar o conceito e os desdobramentos mais imediatos das visões, biocêntrica e antropocêntrica, a fim de ensejar e situar os elementos, que se seguirão a eles.

\section{A PERSPECTIVA BIOCÊNTRICA}

"A Natureza é quem sabe melhor" (COMMONER, I972, p. 20).

Para Robinson (2004), a perspectiva biocêntrica tem suas raízes em dois movimentos culturais, iniciados no século XIX: o transcendentalismo americano e o romantismo europeu. Ambos imprimiram uma visão idílica e espiritualizada sobre a questão ambiental, que perdura até a atualidade, conforme se pode ver nas classificações de Hopwood, Mellor e O'Brien (2005). O biocentrismo se sustenta sobre a premissa fundamental de que a natureza é detentora de direitos, se não maiores, ao menos iguais aos dos homens. Ou seja, o meio ambiente, personificado na ideia de Gaia - um corpo vivo, autorregulado e capaz de reagir a choques externos, como os causados pelo homem (LOVELOCK, I975) -, envolve a humanidade, que dele depende, tornando-a apenas um elemento a mais do ecossistema global. Para os biocentristas, os problemas ambientais presentes e aqueles que se mostram como prováveis, no horizonte futuro, são produtos do modo como a humanidade relaciona-se com a natureza (HOPWOOD; MELLOR; O'BRIEN, 2005). Segundo Hopwood, Mellor e O'Brien (2005), o espectro ideológico e de ação daqueles que perfazem esse grupo parte de uma visão normativo-radical ${ }^{2}$ (ver o ecofascismo e os deep ecologists), que implica, inclusive, o uso da violência contra aqueles que, acredita-se, irresponsavelmente degradam o meio ambiente e estende-se até visões mais parcimoniosas e democráticas, como as chamadas ecofeministas.

Independentemente do grau de radicalismo da perspectiva biocentrista, nota-se que está presente nela o pressuposto de uma ação menos intervencionista do homem na natureza, sustentado sobre a crença de que os recursos naturais não precisam ser gerenciados, mas, sim, preservados. Para esse grupo, a natureza possui uma ordem superior sobre a vontade humana, sendo mais sábia e, portanto, devendo ser deixada livre para seguir seu curso normal. Essa perspectiva, especialmente em seu aspecto mais radical, implica a contraposição à histórica ação fortemente interventiva das populações humanas sobre a natureza. Conforme Banerjee (2003) explica, a reconceitualização de natureza em meio ambiente

David Foreman, fundador do grupo radical escocês Earth First!, chegou a mencionar, a respeito da fome na Etiópia: "a melhor coisa que poderia acontecer era deixar que a natureza encontrasse seu próprio equilíbrio, e deixar as pessoas lá morrerem de fome” (MAUERHOFER, 2008, p. 45). 
torna-a separada das suas origens culturais e sociais e, logo, das práticas locais utilizadas pelas populações nativas de cada região, além de transformar a natureza em "um objeto de interesse científico, ameaçado e carente de proteção, um sistema de provimento de recursos [...]" (BANERJEE, 2003, p. I52).

Normalmente, essa perspectiva é sustentada por acadêmicos, ONGs e outros movimentos civis, dos mais radicais aos mais moderados (HOPWOOD; MELLOR; O'BRIEN, 2005). Estudiosos, como o economista Georgescu-Roegen (I97I), mostram, por meio de análises econômicas, leis da termodinâmica e outras ferramentas teóricas, as fragilidades da "supremacia tecnoeconômica". Por meio desses conhecimentos, eles sustentam que o ecossistema não pode ser totalmente substituído por elementos artificiais e que o crescimento econômico per se não é suficiente para a geração de igualdade social. Faucheux, Froger e Noel (I995) e Kaplinsky (2000) corroboram essa linha de raciocínio. Kaplinsky (2000) analisa as desigualdades econômicas globais, geradas pelo modelo desenvolvimentista liberal. Seus resultados mostram como a globalização dos mercados, antes cativos das organizações estudadas por ele, acabou por permitir uma reorganização das cadeias de valor, de forma a transferir boa parte da geração do valor econômico das cadeias locais para as economias estrangeiras, que passaram a exercer maior controle sobre os seus processos produtivos e comerciais, como um todo. Já Faucheux, Froger e Noel (I995) utilizam um framework integrado para apontar a forte inter-relação existente entre ecossistema, economia e sociedade, sendo os três elementos (formadores do triple-bottom-line) condicionantes e limitantes uns dos outros. A lógica do seu modelo mostra, a exemplo de Georgescu-Roegen (I97I) e Karl-Henrik (2000), que grandes ativos ambientais, como a biosfera, não são substituíveis e que, portanto, devem ser preservados, mesmo que porventura limitando a atividade econômica ou a expansão das populações ao redor do mundo, haja vista que é o sistema ambiental que envolve, sustenta e viabiliza os sistemas social e econômico.

A perspectiva biocêntrica também trata das políticas e dos hábitos de consumo, um aspecto centrado no debate entre necessidades humanas versus desejos humanos (SANNE, 2005; JACKSON, 2005). Mauerhofer (2008), por exemplo, coloca que, consideradas as restrições de crescimento impostas pela esfera ambiental aos sistemas sociais e econômicos - mostradas no seu framework -, aceitar uma redução nos níveis atuais de consumo constitui um passo essencial para obter maior sustentabilidade. O mesmo autor menciona que a suposição central da economia neoclássica, de que o ser humano não tem limites para a sua satisfação - afirmativa testada e contestada por Sanne (2005) -, dificulta a busca por soluções alternativas. Já Buchholz e Rosenthal (2006) mostram a evolução da cultura do consumo, da sua origem até o estado recente, e debatem a sua ética, as suas contradições e os seus impactos sobre o meio ambiente. Além 
das propostas voltadas para um controle mais direto do consumo, via tributação ou regulamentação mercadológica (possibilidades consideradas muito negativas pela maioria das indústrias espalhadas pelo mundo), outros autores oferecem novas possibilidades: Lin (2008), por exemplo, aborda o consumo virtual como um possível canal de satisfação dos consumidores, com uma contrapartida ambiental (footprint) relativamente muito menor do que aquela observada no consumo real. Infelizmente, iniciativas como essa, sustentadas sobre a promessa fundamental de um mundo menos material, não têm atingido seu objetivo. $\mathrm{O}$ próprio Lin (2008) lembra que o consumo de papel em escritórios e a emissão de gases poluentes na atmosfera - para citar apenas dois exemplos - só aumentam com o passar dos anos, mesmo considerando a evolução das tecnologias da informação e da comunicação (TICs) e dos sistemas de transporte.

Outra distinção existente no amplo espectro teórico e prático do desenvolvimento sustentável está no nível de abertura dos processos de tomada de decisão. Embora os biocentristas e aqueles mais centrados em tecnologia e economia (ao menos os moderados), em geral, advoguem por soluções democráticas (EHRENFELD, 2000), observa-se que os primeiros tendem a incentivar uma ação mais coletiva - numa orientação bottom-up -, com maior participação de diversos e variados segmentos sociais (HOPWOOD; MELLOR; O'BRIEN, 2005), do que os antropocentristas. Iyer-Raniga e Treloar (2000), por exemplo, sustentam que uma orientação coletiva é mais adequada à questão do desenvolvimento sustentável, visto que a maioria dos recursos é compartilhada por vários stakeholders, os quais têm diferentes visões sobre como esses recursos devem ser utilizados. Essas diferenças levam, ainda, a uma noção de localidade, ou seja, tais grupos normalmente visam soluções específicas, customizadas para o ambiente local, no qual e para o qual atuam (IYER-RANIGA; TRELOAR, 2000), evitando soluções únicas do tipo "prateleira". Como Robinson (2004) afirma, dada a complexidade e o aspecto dinâmico, situacional e contingencial das esferas social, econômica e ambiental, são necessárias várias abordagens e propostas para o desenvolvimento sustentável. Ou seja, para os biocentristas, não há uma solução final em termos de sustentabilidade (ROBINSON, 2004). Como, de um lado, os padrões de utilização, a movimentação, as políticas de substituição e as próprias taxas de uso dos recursos naturais mudam, de outro, também mudam as dinâmicas sociais e econômicas (empregabilidade, renda, idade da população, entre outras), fazendo-se necessários contínuos ciclos de tomada de decisão ao longo dos anos futuros (IYER-RANIGA; TRELOAR, 2000).

Portanto, é natural que tais grupos adotem uma postura mais marcada pela transdisciplinariedade, a exemplo de Munasinghe (2002), incluindo, por vezes, o incentivo a práticas locais ancestrais, derivadas de conhecimentos não cien- 
tíficos, como aquelas herdadas das antigas tradições indígenas (BANERJEE, 2003), e a visões de mais longo prazo, dado que os efeitos negativos gerados pelo homem na biosfera não são sempre observáveis no curto prazo (KARL-HENRIK, 2000; MAUERHOFER, 2008).

\subsection{A PERSPECTIVA ANTROPOCÊNTRICA}

"O mundo é feito para o homem, não o homem para o mundo" (BACON, I620 apud ROSSI, I968, p. II8).

De forma geral, para a visão antropocêntrica, o meio ambiente é entendido como um conjunto de recursos e serviços para a manutenção e satisfação da vida humana (FAUCHEUX; FROGER; NOEL, I995) que, portanto, deve ser gerido de forma eficiente para garantir sua conservação - e seu consequente serviço - por um período mais longo possível. De modo mais direto, o homem deve reinar sobre a natureza e é o detentor principal de direitos sobre ela.

Essa visão tem sua gênese no inglês Francis Bacon, quando ele rompe com a tradição contemplativa de Aristóteles e Platão, afirmando que conhecimento significa poder para agir sobre o mundo: o mundo deve ser conhecido pela experiência, não pela contemplação. Esse é um dos principais impulsos do utilitarismo científico, que então ganha força e garante a imposição dos sistemas humanos - em especial o tecnológico e o econômico - sobre os sistemas naturais, devendo estes adequar-se àqueles principalmente por meio da ciência (BANERJEE, 2003). No entanto, essa afirmativa encontra diferentes níveis de polarização.

Enquanto um lado do continuum, de certa forma, aproxima-se da perspectiva biocêntrica - e, logo, afasta-se da supremacia tecnológico-econômica -, o outro lado é povoado por boa parte dos governos, das grandes corporações e dos economistas neoclássicos. Esse segundo grupo mantém a crença bem definida de que as evoluções tecnológicas, o aumento do escopo e a eficiência dos mercados são suficientes para projetar, no futuro, um desenvolvimento sustentável duradouro (HOPWOOD; MELLOR; O'BRIEN, 2005). No geral, esse segmento de empresas, instituições e pensadores acreditam na capacidade oferecida pela tecnologia, em substituir os ativos naturais, nas suas funções, biológica, econômica, ou mesmo recreativa (MUNASINGHE, 2002; FAUCHEUX; FROGER; NOEL, I995). O economista vencedor do Prêmio Nobel, Robert Solow (I974, p. Io), bem poderia representar essa ala, dada a sua afirmativa de que, se houver a exaustão de um recurso natural não renovável, isso "não será uma catástrofe, apenas um evento".

Portanto, para os antropocentristas, o consumo crescente não é um proble- 
ma, mas um verdadeiro promotor do desenvolvimento sustentável. Se o crescimento econômico é o motor que levará à sustentabilidade, então, quanto mais consumo houver, melhor será (ROBINSON, 2004). Para o World Business Council for Sustainable Development (I998, p. 4), "podemos ter um sistema de trocas vigoroso, aberto e saudável, e atingir o desenvolvimento sustentável". Ou seja, nessa perspectiva, não há conflito entre consumo e meio ambiente; existe apenas a necessidade de desenvolvimento de sistemas produtivos mais limpos e a criação de produtos mais "verdes", por meio do uso intensivo de tecnologia, aliados à definição e institucionalização de padrões socioecológicos, criados pelos governos e órgãos reguladores do comércio, além do início da taxação dos recursos naturais, por ora extraídos e utilizados sem nenhum tipo de ônus (HOPWOOD; MELLOR; O'BRIEN, 2005).

Adicionalmente, os antropocentristas tendem a voltar sua atenção para a liberdade e para as ações individuais (EHRENFELD, 2000) - ao contrário da postura mais coletivista dos ditos "verdes" -, delegando ao Estado a tarefa de regulamentar as questões inerentes à sustentabilidade e agir mais intensamente sobre elas (BANEERJE, 2003), o que sugere uma atuação do tipo top-down. Ainda, parece haver nesse grupo uma crença ao menos aproximada do tipo one fits all: crescimento econômico e tecnologia seriam suficientes para encarar o desafio da sustentabilidade, seja qual for o local do globo terrestre.

Essa tendência antropocêntrica, de buscar soluções padronizadas, somada à adesão de várias grandes corporações às causas sociais e ambientais, por modismo, slogan ou então incentivadas por uma necessidade de legitimação perante seus clientes e outros stakeholders importantes (BANERJEE, 2003), leva alguns acadêmicos a afirmar que há muito "ambientalismo cosmético" entre as organizações (ROBINSON, 2004). Disso apreende-se que, embora haja organizações sérias e comprometidas com causas sustentáveis, há aquelas que aderem à causa com o intuito velado de se promover ante seus stakeholders ou então para poder manter ou aumentar sua carga de degradação ambiental e social sem serem afetadas por órgãos regulatórios e, ao mesmo tempo, sem perderem participação de mercado (BANERJEE, 2003).

\subsection{UM MUNDO ENTRINCHEIRADO}

A Figura I resume as principais contraposições existentes entre as visões biocentrada e antropocentrada. Ambas as perspectivas estão dispostas em extremos, porém não há separação cartesiana entre elas, de modo que as duas visões posicionam-se em um mesmo continuum. Os elementos citados na referida figura partem dos extremos desta, ou seja, das suas partes mais escuras, à esquerda e à direita. Isso significa que tais posições são representativas dos limites mais 
radicais, tanto para os ecocentrados, à esquerda, quanto para os econômico-tecnocentrados, à direita. Logo, quanto menor for o radicalismo de determinada posição, mais para o centro do continuum esta se encontrará (e menos excludente da abordagem “oposta” ela será), e vice-versa.

\section{FIGURA I}

CONTINUUM INTERLIGANDO AS PERSPECTIVAS

BIOCENTRADA E ANTROPOCENTRADA

\begin{tabular}{|c|c|c|}
\hline \multirow{14}{*}{ 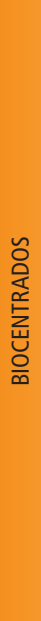 } & Decisões coletivas & Processos mais centralizados, menos participativos \\
\hline & Desenvolvimento sustentável "legítimo" & Desenvolvimento sustentável como "slogan" \\
\hline & Redução de consumo & Aumento da possibilidade de consumo \\
\hline & Necessidades humanas & Desejos humanos \\
\hline & Compatibilidade não-perfeita entre pilares & Pilares são perfeitamente compatíveis \\
\hline & Várias soluções (não há uma solução ideal) & Busca de solução definitiva (best-way) \\
\hline & Localidade e preservação de culturas menores & Cultura global de consumo, soluções amplas \\
\hline & $\begin{array}{l}\text { Ênfase mais em comportamentos e valores do que em } \\
\text { tecnologia e economia }\end{array}$ & Tecnologia e mercados como solução \\
\hline & $\begin{array}{l}\text { Modos alternativos de gerenciamento } \\
\text { (gestão menos interventiva) }\end{array}$ & $\begin{array}{r}\text { Gestão tradicional } \\
\text { (planejamento, controle e medição; mais interventiva) }\end{array}$ \\
\hline & Perspectiva Transdisciplinar & Perspectiva unidimensional \\
\hline & Soluções tipo bottom-up & Soluções tipo top-down \\
\hline & $\begin{array}{l}\text { "A natureza é que sabe melhor". } 0 \text { homem é uma parte da } \\
\text { natureza }\end{array}$ & $\begin{array}{r}\text { "O mundo é feito para o homem, não o homem para o } \\
\text { mundo". O homem domina a natureza }\end{array}$ \\
\hline & Mundo mais complexo & Mundo plano, linear \\
\hline & Academia/ONGs/Organizações Civis & Governos/Corporações \\
\hline
\end{tabular}

Fonte: Elaborada pelos autores.

É importante observar que essa representação não é um modelo normativo e global. Primeiramente, a Figura I não abarca todos os elementos presentes na discussão de desenvolvimento sustentável, mas apenas os principais mencionados na sua literatura. Segundo, a adoção, por quaisquer atores, de uma postura, mais à esquerda ou à direita, em um dos pontos da Figura I, não significa obrigatoriamente que os atores devam aderir a todos os outros pontos dispostos na mesma extremidade do continuum ou então com o seu mesmo nível de intensidade. Entretanto, conforme mostrado nas seções anteriores, a literatura aponta que normalmente a escolha de determinada abordagem, em direção a um sentido (esquerda ou direita), é acompanhada dos outros elementos presentes naquele lado e em intensidades semelhantes. Essas convergências podem ser observadas, em grau maior ou menor, por exemplo, em Banerjee (2003), Ehrenfeld (2000), 
Hopwood, Mellor e O’Brien (2005), Faucheux, Froger e Noel (I995) e, principalmente, em Mebratu (I998).

Para melhor evidenciar a coerência da Figura I e a sua relação com a realidade do desenvolvimento sustentável, será sucintamente apresentado o caso do Greenpeace - extraído de Friedman e Miles (2002) -, uma ONG global fundada, em I97I por um grupo de ambientalistas ativistas engajados na proteção do meio ambiente.

Nos anos que se seguiram à sua fundação, essa ONG mantinha uma relação antagônica com grandes corporações. Seus integrantes, vistos pelo mainstream do mundo dos negócios como excêntricos ou radicais, demonstravam desinteresse em negociar com muitas organizações de grande porte, que mantinham atividades consideradas pelo Greenpeace como predatórias. Por exemplo: pesca de baleias, exploração de florestas e depósitos de resíduos nucleares. Em outras palavras, nesse primeiro momento, o Greenpeace representava posturas vinculadas aos itens presentes à esquerda da Figura I: compatibilidade não perfeita entre os pilares da sustentabilidade (dada a sua postura radical de negação de pontos de vista contrários aos seus) e crença de que a natureza é mais importante ou, ao menos, tão importante quanto o homem.

Na década de I980, iniciou-se uma segunda fase para o Greenpeace, marcada por mudanças importantes nas suas posturas centrais. Essas transformações foram motivadas por vários eventos e desastres ambientais causados por grandes empresas. Esses episódios foram amplamente cobertos pela mídia (buraco na camada de ozônio sobre a Antártida, o desastre atômico de Chernobyl, aumento na frequência e intensidade das chuvas ácidas, grandes vazamentos de óleo nos oceanos, bombardeio de um navio do Greenpeace etc.) e atraíram a atenção de milhões de pessoas ao redor do mundo para a questão ambiental. Assim, o Greenpeace passou a cooptar cada vez mais simpatizantes, ativistas e doadores, os quais geraram forte incremento orçamentário e aumento da área de atuação da maior ONG verde do mundo. O ganho de escala evidenciou a necessidade por uma melhor gestão financeira e por habilidades gerenciais estratégicas, comuns às empresas capitalistas, em geral. Nesse período de fortes mudanças, a captação de um volume crescente de doações tornou-se uma meta constante da organização. Era evidente o esforço para atenuar sua imagem radical, tanto que vários ativistas, mais avessos à nova estratégia da ONG, foram convidados a demitir-se. Assim, na sua nova fase, o Greenpeace migrou para uma orientação mais próxima aos negócios e, portanto, menos antagônica às grandes corporações, anteriormente consideradas inimigas. Chegou-se ao ponto em que parcerias foram estabelecidas, incluindo acordos de patrocínio e exploração de marca. Muito embora isso não significasse um total alinhamento entre as duas partes, observou-se um deslocamento da postura do Greenpeace mais para o centro da Figura I, seja pela 
adoção de métodos mais tradicionais de gestão empresarial, seja por uma maior compatibilidade da sua nova visão com o mundo dos negócios.

O terceiro período do Greenpeace começa durante a década de I990, com o início de um movimento encabeçado por executivos americanos, contrários às políticas e aos ideais ambientalistas da ONG verde. O objetivo dos seus opositores era posicionar o Greenpeace como ameaça real para a sociedade, para os empregos e para a tradição dos negócios. Esses grupos de pressão buscavam mostrar que a legislação ambiental era excessivamente cara para as organizações e destacavam o fato de os movimentos ambientais apenas apontarem problemas, sem a contrapartida do oferecimento de soluções. Os integrantes do Greenpeace foram rotulados como terroristas ambientais, chantagistas e insensíveis às questões sociais. A consequência disso foi a queda abrupta do número de adeptos da entidade (em torno de 81\% somente nos Estados Unidos). O cenário desfavorável fez o Greenpeace buscar uma nova configuração, ainda mais próxima das aspirações do público empresarial.

Ainda na década de I990, concomitantemente ao surgimento do "Novo Greenpeace", ganha força o ideal do desenvolvimento sustentável como uma possível via para a busca de soluções parcimoniosas e, portanto, viáveis. Esse fato parece ter tido algum efeito em retomar a sensibilidade dos governos e do público em geral para as questões ambientais, mas, dessa vez, influenciando também grandes corporações, fortemente marcadas por ideais antropocentrados. Surge uma nova configuração na relação entre entidades ambientais e indústrias. A partir de então, as empresas passaram a ser avaliadas por questões éticas e ambientais. Por meio de suas políticas de responsabilidade social e corporativa (RSC), muitas organizações privadas de grande porte aceleraram a aproximação às organizações verdes, estabelecendo cada vez mais alianças estratégicas com ONGs e outras entidades promotoras da proteção ambiental. O Greenpeace seguiu o mesmo movimento, passando a atuar em estreita colaboração com grupos empresariais para a criação de soluções, amparadas na ação coletiva e no compromisso mútuo. Dessa forma, nessa terceira fase, mais uma vez o Greenpeace muda sua postura, em um movimento direcionado ainda mais para o centro do continnum. Entretanto, essa mudança não foi unilateral: corporações, governos, sociedades e outros stakeholders, que antes estavam mais à direita da Figura I, também fizeram concessões importantes que os posicionaram mais em direção ao centro da interface - biocentrado e antropocentrado - não necessariamente com a mesma magnitude. A Figura 2 ilustra os três momentos relatados. Para fins de simplificação, a ilustração aponta apenas os elementos citados no exemplo, e as três fases de mudança são representadas, respectivamente, por I, 2 e 3. A representação das mudanças dos antropocentrados (o público empresarial americano) assume a forma de três grandes elipses, pelo fato de todos os elementos terem sido afetados em todas as três fases. 
FIGURA 2

\section{GREENPEACE, PÚBLICO EMPRESARIAL AMERICANO E SUAS TRÊS FASES DE MUDANÇA}
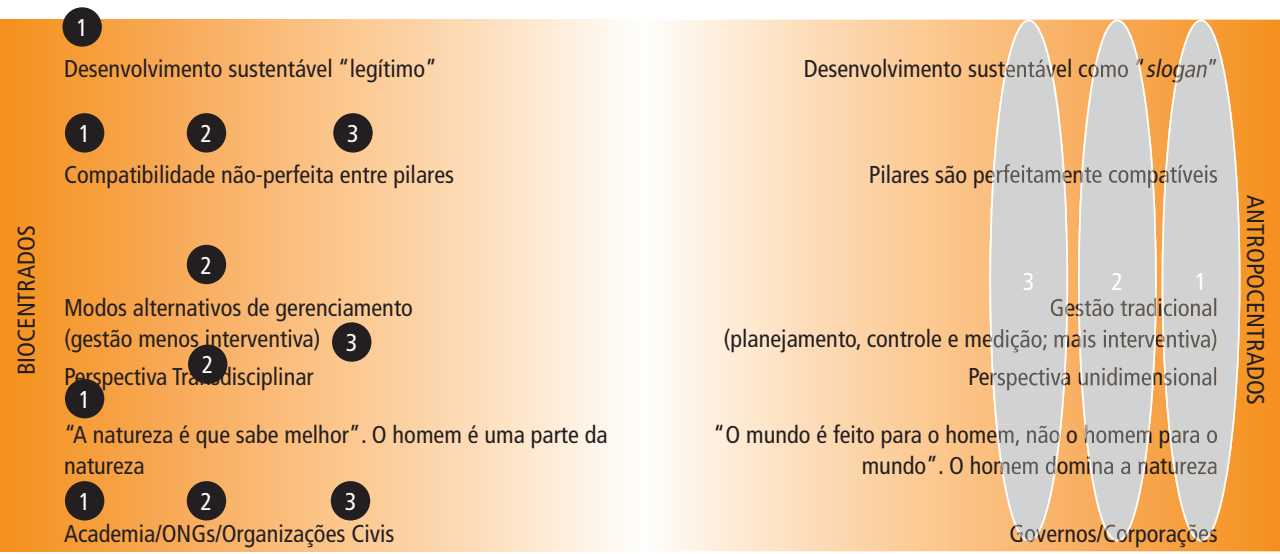

Fonte: Elaborada pelos autores.

Apresentada e exemplificada a Figura 2, que localiza biocentrados e antropocentrados em campos opostos do desenvolvimento sustentável, resta ainda discutir como as suas contradições centrais podem ser posicionadas e discutidas, a partir de um modelo analítico-decisório racional que permita a aproximação dessas visões, a priori antagônicas entre si.

\section{INTEGRANDO AS DUAS GRANDES VISÕES}

É importante retomar o fato de que as perspectivas antropocêntrica e biocêntrica partem de visões de mundo fundamentalmente diferentes. Disso decorre que o debate sobre sustentabilidade é fragmentado, muitas vezes marcado por conflitos abertos e informações antagônicas ${ }^{3}$, mutuamente excludentes (HOPWOOD; MELLOR; O'BRIEN, 2005), conforme apresentado. Diferentes objetivos, expostos e velados - por vezes, diametralmente opostos -, sofrem interferências de interesses ideológicos, políticos, culturais e econômicos, e por isso são perseguidos de modos diversos. Em outras palavras, se não houver algum tipo de aproximação maior entre os dois extremos expostos no continuum

Ver, por exemplo, o escândalo ocorrido antes da realização da COPI5, em 2009, na Dinamarca. Supostas alterações artificiais de dados climáticos fomentaram sérios questionamentos a respeito da seriedade das pesquisas climáticas lideradas ou apoiadas por grandes órgãos globais. 
da Figura I, as esperanças por soluções realmente viáveis tenderão a diminuir consideravelmente. Portanto, há a necessidade de uma nova configuração: uma perspectiva de análise e decisão inovadora que permita a coexistência ou, ao menos, uma melhor acomodação mútua de elementos e motivações, por vezes paradoxais. Esse é o objetivo dos próximos tópicos, nos quais são apresentadas e sistematizadas diferentes teorias, relacionadas ao desenvolvimento sustentável. Em seguida, será mostrado como sua consideração conjunta forma o modelo conceitual para a análise e a decisão gerenciais.

\subsection{A ECOLOGIA INDUSTRIAL COMO FUNDAÇÃO PARA UM NOVO MODELO DE DECISÃO SUSTENTÁVEL}

Segundo vários autores (JELINSKI et al., I992; ERKMAN, I997; COHEN-ROSENTHAL, 2000; EHRENFELD, 2000; HOFFMAN, 2003; ISENMANN, 2003; KORHONEN, 2004), a ecologia industrial parte da metáfora da natureza para analisar e aperfeiçoar os complexos industriais, logísticos e de consumo, seus fluxos energéticos e materiais. De acordo com Isenmann (2003), a ecologia industrial nasce da aspiração humana de integrar seus próprios sistemas artificiais com os sistemas presentes nos hábitats naturais, de modo a permitir a criação de arranjos produtivos e de consumo realmente sustentáveis. Em outras palavras, a ecologia industrial não foi desenhada para compactuar com a insustentabilidade, nem para atenuá-la (EHRENFELD, 2000) - sua força está exatamente no seu caráter normativo.

A ecologia industrial oferece uma visão holística que considera as mais amplas necessidades de Gaia e dos homens (não só os econômicos, mas também os sociais), concomitantemente. Essa teoria espelha uma série de elementos diretamente observados nos sistemas naturais, como a coopetição*, a conectividade, a comunidade, os circuitos fechados (loop closing), a reciclagem - esta normalmente posicionada no final dos ciclos produtivos - e os sistemas steady state (EHRENFELD, 2000), em que a produção de entropia é mínima, ao contrário do equilíbrio dinâmico neoclássico. De acordo com Isenmann (2003), a ecologia industrial pode ser compreendida, em termos gerais, por suas cinco características mais marcantes: I. sua perspectiva fundamental: ver a natureza como modelo; 2. seu objetivo primordial: equilibrar sistemas industriais e ecossistemas naturais; 3. sua definição de trabalho: uma ciência da sustentabilidade; 4. seus objetos principais de trabalho: produtos, processos, serviços e resíduos; e 5. sua ideia central, seu cerne: a busca pela simbiose industrial, definida como

* Não há correspondente exato em português para o termo coopetition, ou co-opetition, que significa os movimentos concomitantes de colaboração e competição que eventualmente regem relacionamentos interpessoais e interorganizacionais. Daí o uso do neologismo "coopetição". 
o entrelaçamento de sistemas industriais e naturais, em que sistema industrial é um tipo específico de ecossistema, com distribuição particular de materiais, energia e fluxo de informações (ERKMAN, 1997).

Já Jelinski et al. (I992) reforçam a necessidade de considerar a perspectiva transversal e abrangente da ecologia industrial: sua aplicação envolve processos de engenharia, sistema econômico, tributação, regulamentação governamental, padrão de vida do consumidor, análise do ciclo de vida dos produtos, evolução tecnológica, entre outros fatores culturais e sociais, que se estendem para muito além das fronteiras de apenas uma organização, demandando uma visão compartilhada dos stakeholders envolvidos (COHEN-ROSENTHAL, 2000). As múltiplas e concomitantes visões, presentes na ecologia industrial, constituem um dos seus pontos mais fortes: filosofia, ética, economia, ecologia, biofísica e gestão, entre outros campos do conhecimento, unidos em uma concepção única, transdisciplinar (ISENMANN, 2003).

Para Isenmann (2003), a viabilidade de tais visões pressupõe três atributos: I. perspectiva sistêmica e integrada de todos os materiais e componentes energéticos da economia industrial, e relações com a biosfera; 2. substrato biofísico das atividades industriais, representando todos os fluxos de material e energia do sistema produtivo; e 3. progresso tecnológico em consonância com mudanças sociais e culturais, representando o trifólio do desenvolvimento sustentável a interdependência entre: progresso tecnológico, crescimento econômico e mudança social, como precondições para o desenvolvimento socioeconômico.

Mas qual é o impacto da ecologia industrial sobre as visões contrapostas apresentadas na Figura I? Essencialmente, pode-se esperar que as características inerentes à ecologia industrial (interdependência, comunidade, coopetição e sistemas em circuito fechado) pressionem por uma reconfiguração na distribuição dos elementos constituintes da Figura I e permitam a atenuação dos eventuais radicalismos existentes, de forma a gerar uma acomodação maior entre os vários interesses de biocentrados e antropocentrados. Não há a ilusão de que a ecologia industrial promova a unificação total de interesses tão distintos. No entanto, embora a ecologia industrial não tenha a plena capacidade de gerar a unanimidade, ela permite uma convivência mais "orgânica" - refletindo sua própria natureza - entre os vários elementos presentes na Figura I. Principalmente, ela aumenta a viabilidade de coexistência das lógicas "natural" e de "mercado" em um mesmo sistema produtivo (considerados certos limites, certamente). Erkman (I997), por exemplo, menciona que a aplicação dos princípios da ecologia industrial pode resultar em vantagem competitiva, dada a necessidade de aumento de eficiência na utilização de energia e materiais, como também de eliminação de perdas, enquanto, ao mesmo tempo, é uma ferramenta com características claramente ambientais e sociais. 
Entretanto, dada a multiplicidade de condições e atores envolvidos nos sistemas produtivos e comerciais, é provável que a convivência de seus interesses continue, em certo grau, marcada por pressões, conflitos, desajustes e contradições, embora possivelmente atenuados pela lógica integrativa da ecologia industrial. A ecologia industrial representa, então, um avanço integrativo importante, se comparada, por exemplo, à lógica "pura" das cadeias de suprimentos, baseada na otimização de recursos, ou quando comparada aos ecologistas mais radicais, desejosos de uma natureza utopicamente intocada (HOPWOOD; MELLOR; O'BRIEN, 2005). A Figura 3 representa essa aproximação entre diversos interesses, mostrando uma maior possibilidade de coexistência entre os objetivos de vários stakeholders, presentes no contexto decisório.

Entretanto, a ecologia industrial, por si só, ainda não é suficiente como mecanismo de integração entre os "dois mundos contrários", anteriormente apresentados, pois se faz necessário antes entender os principais aspectos que fundamentam a localização dos seus marcos decisórios, os quais, por sua vez, impactam nos movimentos de adaptação mútua das duas perspectivas mencionadas. Sem um conjunto normativo mínimo para direcionar as tomadas de decisão, os desacordos entre opostos tendem a perdurar, protelando cada vez mais a criação de uma visão conjunta e a ação efetiva sobre as lacunas existentes, em termos de sustentabilidade (EHRENFELD, 2000; KARK-HENRIK, 2000).

\section{FIGURA 3}

\section{APROXIMANDO AS PERSPECTIVAS BIOCENTRADA E ANTROPOCENTRADA A PARTIR DA LÓGICA DA ECOLOGIA INDUSTRIAL}

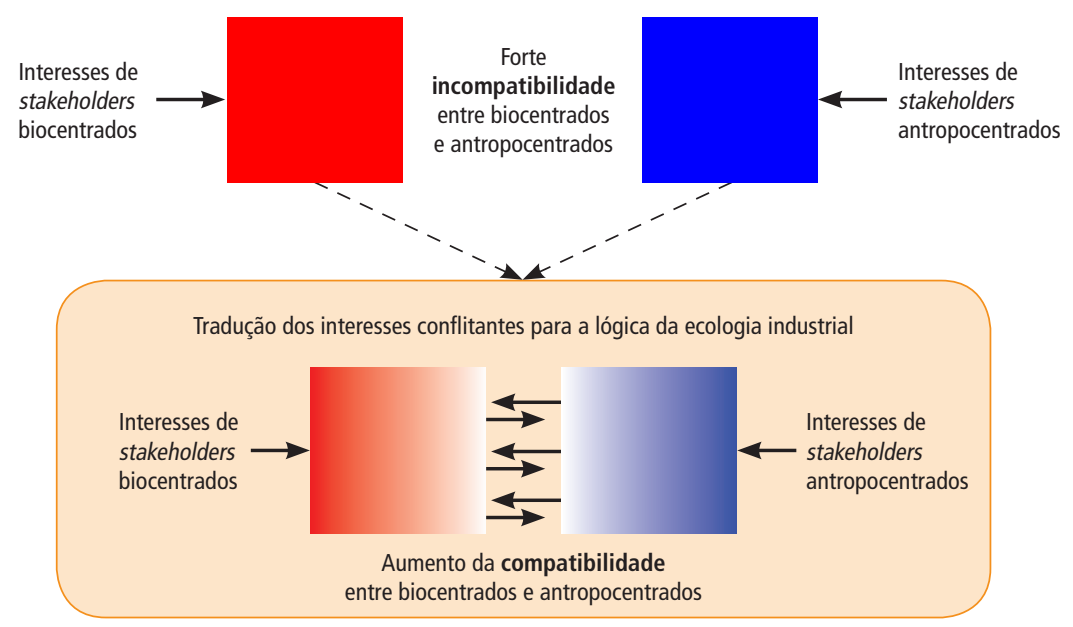

Fonte: Elaborada pelos autores. 
Como exemplo, considere o debate sobre os danos ambientais um ponto central de interesse para as teorias e políticas de sustentabilidade. Se for perguntando a um ecologista radical o que é um "dano" ambiental, é provável que ele acuse todas as intervenções humanas menores sobre o hábitat natural como sendo uma ofensa à Gaia. Em sentido inverso, caso o mesmo questionamento seja feito ao proprietário de uma grande madeireira, por exemplo, a resposta provavelmente será bastante diferente. Portanto, é vital entender o papel dos grupos de interesse (stakeholders) envolvidos nesse contexto. É esse o foco do próximo tópico.

\subsection{STAKEHOLDERS: INTEGRANDO A PERSPECTIVA DA ECOLOGIA INDUSTRIAL}

Como foi apresentado, os stakeholders desempenham um papel central na definição, defesa e operacionalização dos diferentes conceitos de desenvolvimento sustentável, afinal, são os seus interesses, posições e embates que preenchem o campo de discussão e prática da sustentabilidade (KERKHOF; WIECZOREK, 2005). Em termos conceituais, um stakeholder é qualquer indivíduo ou grupo que mantém um determinado interesse nas ações e repercussões de uma organização (FASSIN, 2008). O mesmo autor também considera a teoria dos stakeholders como uma poderosa ferramenta para ampliar a visão organizacional para além da maximização dos seus lucros. Dessa forma, ele parte da concepção clássica de stakeholder, de Freeman (I984), para propor uma nova visão do conjunto e da interação desses atores - ilustrada na Figura 4.

\section{FIGURA 4}

\section{ORGANIZAÇÃO E SEUS STAKEHOLDERS}

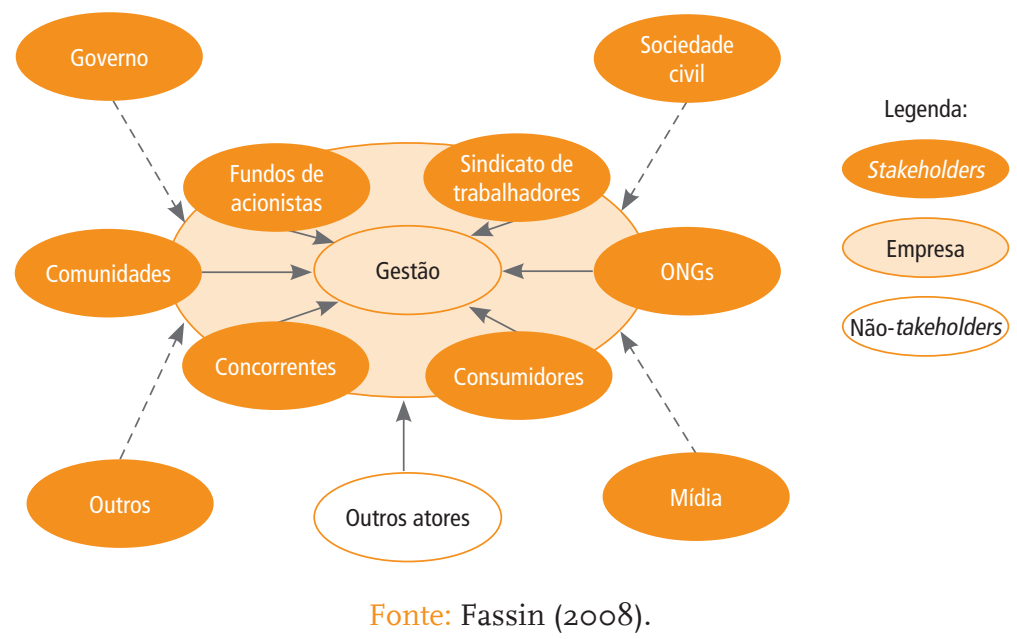


Ante a problemática focada neste trabalho, a Figura 4 evidencia a necessidade de as práticas de desenvolvimento sustentável considerarem a análise de componentes externos às organizações, em complemento às suas realidades internas. Adicionalmente, a abordagem dos stakeholders pode auxiliar na modelagem da trajetória estratégica organizacional, de modo a facilitar a abordagem conjunta das perspectivas antropocêntrica e biocêntrica, facilitando a aproximação de ambas no contexto das ideias da ecologia industrial.

Outro ponto a destacar, quanto aos stakeholders, concentra-se na capacidade de legitimação, no papel e nas diferentes pressões exercidas por eles. Normalmente, quanto maior a legitimidade de um stakeholder ante as organizações e os outros públicos de interesse, maior é a sua capacidade de pressão sobre eles (FASSIN, 2008). Segundo esse mesmo autor, os três principais papéis dos stakeholders são:

- Os próprios stakeholders, que têm interesse real e positivo na firma (são os stakeholders no sentido clássico do termo).

- Os stakewatchers (“cães de guarda”), que não têm interesse imediato na organização, mas que protegem os interesses dos stakeholders.

- Os stakekeepers (reguladores independentes), os quais estão ainda mais distantes dos stakeholders, porque não mantêm interesses imediatos e específicos na organização, mas exercem influência e controle sobre ela por meio da imposição de limitações e mecanismos regulatórios (órgãos governamentais de regulamentação, por exemplo).

Mais adiante, será apresentado como os stakeholders participam ativamente na construção do desenvolvimento sustentável e como o seu desempenho é determinante para o modelo conceitual analítico-decisório, proposto neste artigo. Porém, antes, é necessário que a sustentabilidade seja sistematizada em um quadro de referência que possibilite a inserção desses atores, conforme se verá a seguir.

\subsection{UMA VISÃO SISTÊMICA PARA O DESENVOLVIMENTO SUSTENTÁVEL: 0 TRIÂNGULO 3-D E A HIERARQUIA DECISÓRIA DE MAUERHOFER}

Dado que as perspectivas de desenvolvimento sustentável tendem à bipolaridade (antropocentrado e biocentrado), que a ecologia industrial é uma ferra- 
menta que pode auxiliar na aproximação desses objetivos divergentes, os quais são perseguidos pelos diversos stakeholders organizados em diferentes grupos de interesse e pressão, há ainda a necessidade de considerar elementos teóricos que complementem essas perspectivas e permitam a sua sistematização. O objetivo deste tópico é apresentar esses elementos, que serão posteriormente articulados às teorias já discutidas, para a formação do modelo analítico-conceitual proposto neste artigo. O primeiro deles é intitulado triângulo 3-D por Mauerhofer (2008, p. 496):

O triângulo 3-D é uma nova abordagem para avaliar hierarquias e conjuntos de prioridades relacionadas à sustentabilidade ambiental, social e econômica [...] esse conceito introduz e hierarquiza critérios para a avaliação das três dimensões da sustentabilidade. Esses critérios são aplicados a várias [...] soluções de conflito de interesses.

Essa construção está representada na Figura 5. O triângulo, que abrange todos os outros elementos representados, reflete a biosfera global, com todos os seus recursos naturais: é a capacidade total de resiliência do meio ambiente (os seus limites). É ele que mantém o equilíbrio da vida. Comprometê-lo significa comprometer as dimensões social e econômica da sustentabilidade, que dele dependem para existir. A base do triângulo é formada por três círculos sobrepostos. O círculo mais externo representa o capital natural; o intermediário, o capital social; e o do centro, o capital financeiro (este elemento está no centro da pirâmide, não porque é o mais importante, mas porque ele só pode existir a partir dos sistemas, ambiental e social). Esses três círculos informam a quantidade de ativos que cada um desses elementos possui. Todas as três circunferências são dinâmicas (assim como todo o modelo): podem aumentar ou diminuir de acordo com a utilização dos recursos que os preenchem, impactando todo o triângulo. As barras que se erguem sobre cada um dos círculos mostram a capacidade e o nível de utilização desses ativos. Já o triângulo inclinado no sentido horizontal, que está sobre as três barras, representa o equilíbrio ou desequilíbrio da sustentabilidade como um todo e é produto dos níveis de efetividade e eficiência econômica, social e ambiental, que todo o sistema está produzindo. 


\section{FIGURA 5}

\section{TRIÂNGULO 3-D DA SUSTENTABILIDADE}

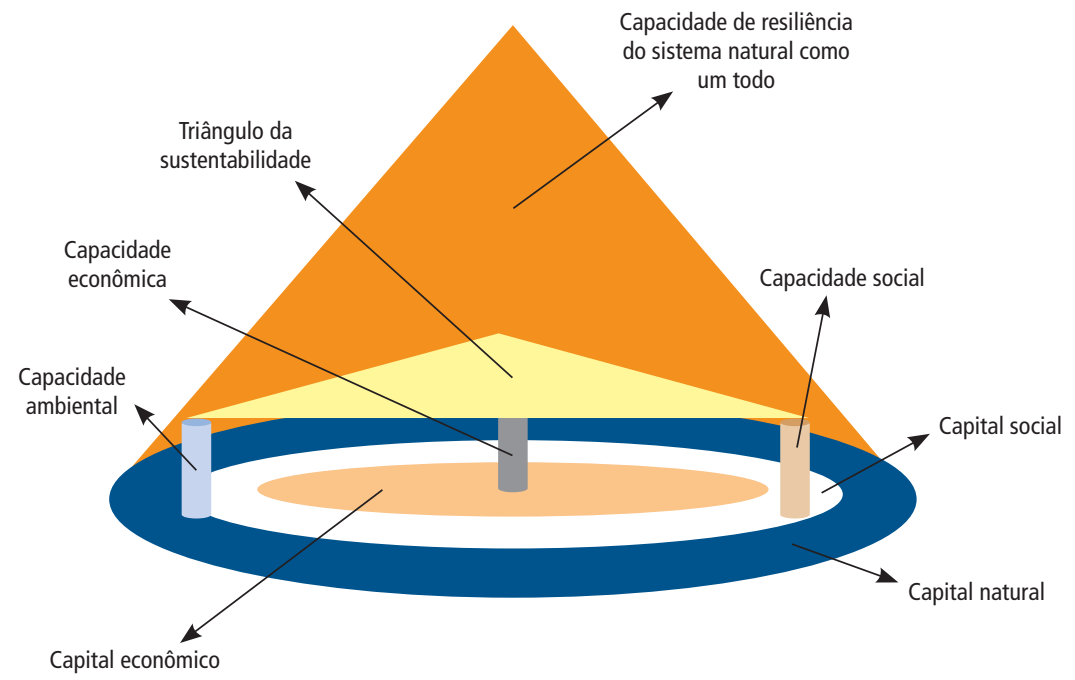

Fonte: Mauerhofer (2008).

O modelo de Mauerhofer $(2008)^{4}$ permite conceituar, em termos normativos, o que é um "dano" à sustentabilidade, solucionando impasses importantes entre biocentrados e antropocentrados: "dano" é toda a ação que comprometa a capacidade de resiliência do sistema como um todo. Essa afirmativa precisa ser entendida de forma ampla, considerando todos os aspectos sociais, ambientais e econômicos.

Assim, a Figura 5 mostra que há uma clara inter-relação entre os três macrossistemas (ambiental, social e econômico), organizados em ordem decrescente de importância, visando a sustentabilidade do planeta como um todo. Se a biosfera for comprometida, colapsarão também os sistemas social e econômico, inviabilizando a vida humana no planeta (MEBRATU, I998; KARL-HENRIK, 2000; FAUCHEUX; FROGER; NOEL, I995). Essa ordenação das dependências exige, portanto, uma hierarquia decisória que a espelhe, de modo a reduzir o risco de geração de uma espiral negativa de desestabilização e destruição do sistema natural e, consequentemente, da vida humana. A discussão e a viabilidade dos diversos interesses de ecocentrados e tecnoeconômico-centrados devem submeter-se a essa mesma hierarquia, que assume então o papel de marco decisório dos seus pontos de vista distintos. Embora vários outros autores - entre os quais

4 Propostas semelhantes podem ser vistas em Mebratu (I998) e Karl-Henrik (2000). 
Faucheux, Froger e Noel (I995) e Karl-Henrik (2000) - tenham propostos modelos decisórios para a sustentabilidade, este trabalho utiliza a hierarquia decisória do próprio Mauerhofer (2008), ilustrada na Figura 6, dada a compatibilidade com seu triângulo 3-D.

\section{FigURA 6}

HIERARQUIA DE PRIORIDADES PARA

O DESENVOLVIMENTO SUSTENTÁVEL

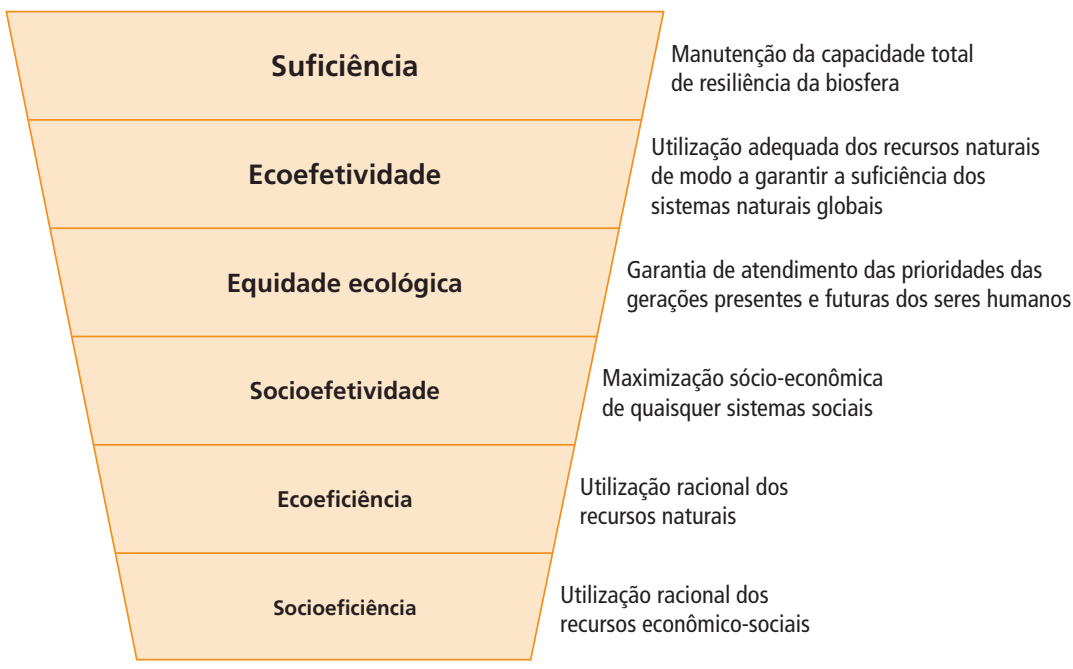

Fonte: Adaptada de Mauerhofer (2008).

Essa hierarquia informa quais aspectos da sustentabilidade devem ser priorizados para assegurar a sobrevivência de todo o sistema (representado no triângulo 3-D). Assim, a suficiência e a ecoefetividade têm influência direta na capacidade de carga ambiental, enquanto a equidade ecológica e a socioefetividade lembram que a manutenção do capital social é precondição ao capital econômico. O próprio Mauerhofer (2008) salienta que a ecoeficiência e a socioeficiência não precisariam estar nessa lista se as condições hierárquicas superiores fossem sempre atendidas.

Entretanto, essa hierarquização não é fixa: está sujeita a mudanças na ordenação dos seus elementos, o que pode ocorrer desde que o proponente à mudança ofereça o que Mauerhofer (2008) denomina “ônus da prova”. Como a hierarquia foi construída de modo a garantir a perenidade de todo o sistema, é importante que a priorização de um nível inferior à Figura 6 só ocorra mediante a apresentação 
das evidências de que todos os níveis superiores não serão comprometidos pela mudança. O ônus da prova faz com que as demandas de stakeholders e de organizações, que proponham essa inversão de parâmetros, não possam ser levadas adiante, em detrimento do equilíbrio do sistema como um todo. Essa hierarquia decisória, portanto, cumpre papel-chave, na busca pela equidade dinâmica entre os três pilares da sustentabilidade e os interesses de biocentrados e antropocentrados.

\section{UM MODELO CONCEITUAL ANALÍtICO- DECISÓRIO PARA O DESENVOLVIMENTO SUSTENTÁVEL}

A sistematização das teorias da sustentabilidade, discutidas no presente artigo, (ecologia industrial, stakeholders e triângulo 3-D da sustentabilidade, incluindo sua hierarquia decisória) preenche a proposta central deste estudo: o modelo conceitual analítico-decisório integrado para o desenvolvimento sustentável (Figura 7), que visa desentrincheirar biocentrados e antropocentrados. Assim, neste tópico será proposto um modelo normativo e abrangente, passível de adaptação aos diferentes contextos organizacionais existentes. Sua natureza difere fundamentalmente dos modelos propostos, por exemplo, por Waage et al. (2005) e Robert, et al. (2002), que propõem ferramentas operacionais para o desenvolvimento sustentável.

O modelo proposto se divide em três fases sequenciais. Na sua primeira fase, sugere-se a consideração conjunta das demandas dos diversos tipos de stakeholders que mantêm alguma pressão sobre a organização. Nesse momento, deve ser feita uma primeira triagem, com o subsequente agrupamento das demandas em grupos comuns. Após, para que haja maior efetividade do processo de gerenciamento, esses grupos precisam ser priorizados de acordo com sua ordem de relevância, visto que dificilmente as organizações terão capacidade de gerenciá-las concomitantemente.

Neste momento, inicia-se a segunda fase do modelo. Todos os grupos contendo as exigências dos vários tipos de stakeholders devem, um a um, ser submetidos à hierarquia decisória da sustentabilidade (conforme apresentada na Figura 6). Por esse processo, devem ser entendidos os impactos potenciais que o seu eventual atendimento trará à sustentabilidade como um todo. Aqueles grupos de demandas que não atenderem às exigências de todos os níveis da hierarquia devem ser renegociados junto aos seus respectivos stakeholders, que arcam sempre com o "ônus da prova”. Ou seja - salvo casos regulatórios - esses 


\section{FIGURA 7}

\section{MODELO CONCEITUAL ANALÍTICO-DECISÓRIO PARA O DESENVOLVIMENTO SUSTENTÁVEL}

- Fase 1: Análise das demandas dos diversos stakeholders frente à organização

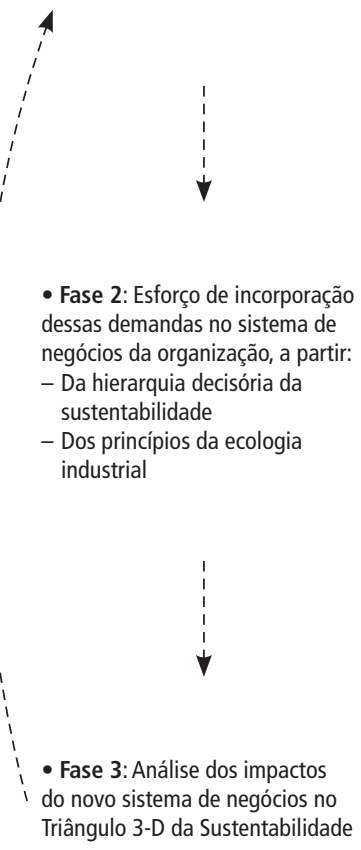

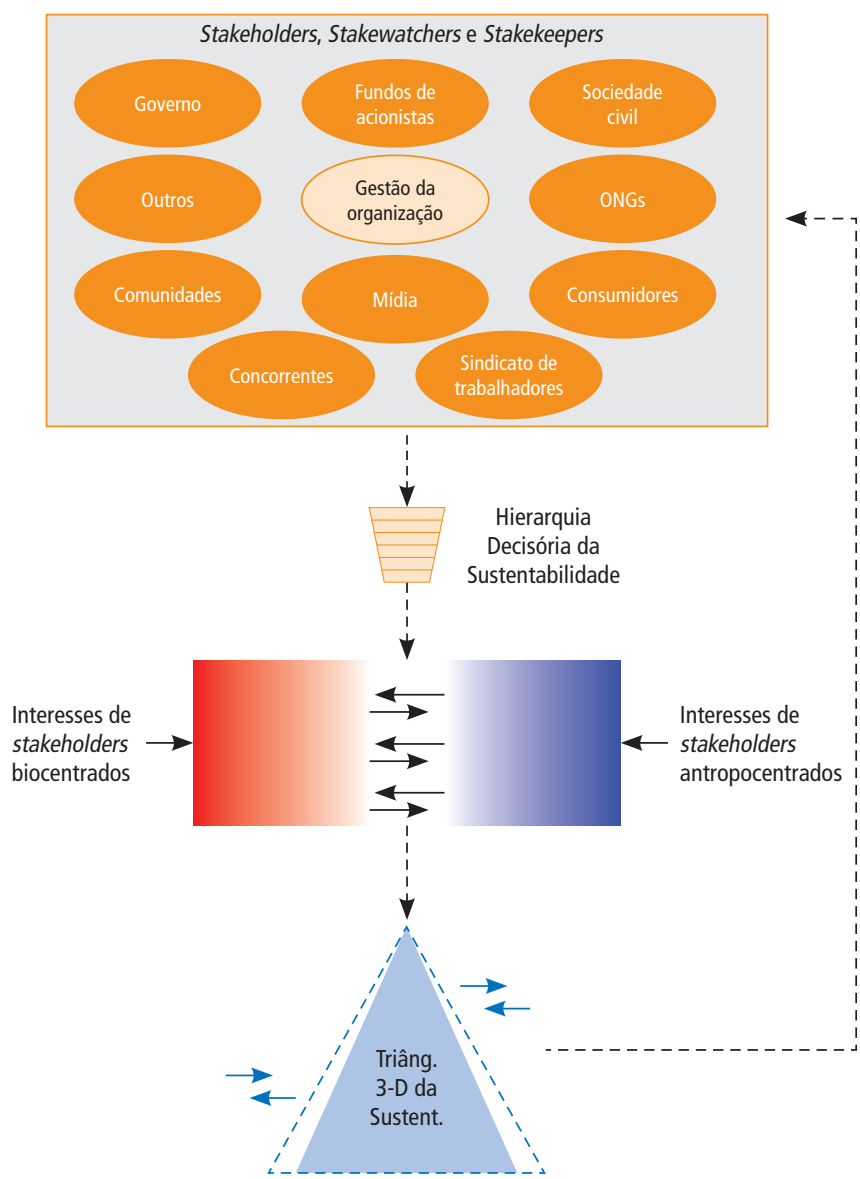

Fonte: Elaborada pelos autores.

stakeholders devem comprovar que suas demandas respeitam todos os níveis da hierarquia decisória. Por sua vez, os grupos de demanda aprovados com sucesso por todas as etapas da hierarquia devem, agora, ser incluídos no sistema de negócio da organização. Para tanto, a organização precisa assimilar e traduzir esses novos requisitos - os quais podem ser de caráter biocentrado ou antropocentrado - para a sua própria realidade operativa, a partir dos princípios da ecologia industrial, discutidos anteriormente. A adequação do conjunto de demandas potencialmente conflitantes dos vários stakeholders à ecologia 
industrial deve garantir uma maior possibilidade de coexistência efetiva das demandas de "verdes" e "tecnocapitalistas"; a utilização da ecologia industrial como pano de fundo para os novos processos também deve garantir que a sua operacionalização não causará desequilíbrios - essencialmente ambientais - à sustentabilidade dos territórios afetados, diretamente ou mesmo mais indiretamente, pela organização.

A terceira e última fase do modelo conceitual analítico-decisório é iniciada após a implementação dos novos processos derivados das demandas de diversos stakeholders. Nesse momento, o objetivo primeiro é mensurar os seus impactos sobre a realidade abrangente da organização, dos seus diversos stakeholders e do ecossistema circundante a ambos (conforme demonstra o triângulo 3-D da Figura 5). Embora a expectativa seja de que ocorram impactos negativos mínimos sobre a sustentabilidade em si mesma (dadas as considerações anteriores referentes à hierarquia decisória e à ecologia industrial), é bastante provável que mudanças organizacionais alterem o equilíbrio interno do triângulo 3-D, visto que possivelmente haverá alterações na relação entre os capitais e as capacidades econômicas, sociais e ambientais. A reconfiguração desses elementos, por sua vez, pode implicar mudanças na organização e nos interesses do conjunto geral dos seus stakeholders, de modo a mudar suas prioridades, atrair novos grupos de interesse para o horizonte organizacional ou, então, "desconectar" stakeholders anteriormente vinculados à organização - reiniciando um novo ciclo do modelo analítico-decisório.

Adicionalmente, deve-se considerar que o aspecto dinâmico do modelo reflete o fato de que o desenvolvimento sustentável não é um elemento estático, mas um processo permanente (MEBRATU, I998). Como os aspectos sociais, econômicos e ambientais, presentes nas diversas sociedades, estão em permanente transformação, é improvável existir uma solução definitiva para a questão da sustentabilidade (o equilíbrio permanentemente satisfatório entre essas três esferas). O mais provável é o movimento contínuo dos elementos irredutivelmente conectados na Figura 7, refletindo estados de maior ou menor desequilíbrio interno do triângulo 3-D.

\section{CONSIDERAÇÕES FINAIS}

Entende-se que o presente ensaio traz duas contribuições principais ao corpo de conhecimentos do desenvolvimento sustentável. Inicialmente, por meio da sistematização do trabalho de vários autores sobre a temática, foi apresentado como a maior parte dos estudos sobre o desenvolvimento sustentável posicio- 
na-se no campo do debate teórico. Mostrou-se como as perspectivas presentes em governos, ONGs, academia, sociedade civil e outros grupos de interesse tendem a se acomodar em dois grupos de opinião e ação profundamente diferentes, quando não completamente incompatíveis entre si. Foi mostrado como essas contraposições operam entre si e como, muitas vezes, atravancam o avanço na construção de uma teoria e um corpo de ações coerentes para o desenvolvimento sustentável.

A Figura I, derivada dessa discussão, oferece ao leitor uma ferramenta útil para analisar os vários argumentos que se fazem presentes no debate sobre o desenvolvimento sustentável, possibilitando um melhor entendimento das lógicas que movem os discursos biocentrados e antropocentrados.

A segunda e maior contribuição deste ensaio concentra-se na construção de um modelo conceitual analítico-decisório (Figura 7). Consideradas as suas características e o seu funcionamento, esse modelo pode oferecer maiores possibilidades de convergência entre os interesses, antes fortemente antagônicos, de biocentrados e antropocentrados, em direção a visões e ações conjuntas e, portanto, com maior chance de sucesso. Concebido em forma de circuito fechado, esse modelo fundamenta-se sobre uma heurística conceitual que reflete a própria natureza recursiva, interdependente e dinâmica do desenvolvimento sustentável, considerando também seus aspectos normativos, como a escassez dos recursos naturais e sua relação com a capacidade de resiliência da biosfera.

Dado o ineditismo desse modelo conceitual, sugerem-se alguns estudos futuros: I. o desenvolvimento operacional e a posterior aplicação de uma ferramenta analítico-decisória sobre os principais argumentos de biocentrados e antropocentrados, presentes nos mais diversos foros de discussão, de modo a verificar qual seria o grau de aproximação possível de ser atingido com sua utilização; e 2. a adaptação do referido modelo a indústrias específicas, entretanto, mantendo as suas mesmas premissas fundamentais.

Essas duas principais contribuições são produtos de um esforço teórico que visa agregar à literatura existente perspectivas e ferramentas, as quais auxiliem na convergência das visões existentes de desenvolvimento sustentável para a geração de ações mais efetivas, visto que a sustentabilidade é cada vez mais importante e urgente, tanto local quanto globalmente. E, embora existam várias divergências entre os "verdes" e aqueles ditos "do mercado", ambos parecem compartilhar de um mesmo desejo: a sobrevivência da raça humana. 


\section{COMING OUT THE SUSTAINABLE DEVELOPMENT TRENCH: A NEW PERSPECTIVE FOR ANALYSIS AND DECISION IN SUSTAINABILITY}

\section{ABSTRACT}

The sustainable development is entrenched. Your field is characterized by conflicting visions and interests that provide feedback for its fragmentation in two main ideological groups which oppose one another. In one trench are the biocentered, who advocate for the prioritization of natural resources preservation over socio-economic systems; the other trench is occupied by the antropocentered, moved by the belief that Nature exists to serve men and that market growth and technological evolution are enough to create sustainability. This loggerheads makes more difficult to construct a common vision for sustainable development, what results in slow advancement, if not in regress for a bigger equilibrium between economy, society and environment all over the world. Then there is the necessity to reduce the gap between these two vision, so that will make room for actions and politics towards a viable sustainable development. This paper aims: to propose a new conceptual perspective for sustainable analyses and decision, which allows a closer approach of both visions. From a "general map", where we track biocentered and antropocentered actors in opposite fields, we begin the construction of the conceptual model. The industrial ecology perspective is integrated to the stakeholders theory and to the Mauerhofer's (2008) 3-D sustainability for the construction of it, which is conceived to reflect instrinsic sustainable development characteristics and it works as a closed circuit, retrofitted. This model fulfills this paper's objective and is its main contribuition. We suggest the following advancements: $\mathrm{I}$. the model operation development and its ulterior application over the biocentered and antropocentered main demands, present in the diverse discussion forums; and 2. the model adaptation to specific industries.

\section{KEYWORDS}

Sustainable development; Analytic and decision model; Biocentered; Antropocentered; Industrial ecology. 


\section{SALIENDO DE LA TRINCHERA DEL \\ DESARROLLO SOSTENIBLE: UN NUEVO \\ MODELO PARA EL ANÁLISIS Y LA DECISIÓN \\ SOSTENIBLE}

\section{RESUMEN}

El desarrollo sostenible está en una trinchera. Su campo está marcado por las visiones e intereses contrapuestos que pasan a engrosar la fragmentación del tema en dos grandes grupos ideológicos que se oponen. En una trinchera están los biocentrados, abogando por el establecimiento de prioridades de conservación de los recursos naturales en los sistemas socio-económicos, y la otra trinchera está ocupada por los antropocentricos, impulsados por la creencia de que la naturaleza existe para servir al hombre y que el crecimiento de los mercados y mejora de la tecnología son suficientes para generar la sostenibilidad. Este contraste hace que sea difícil de construir una visión compartida para el desarrollo sostenible, dando como resultado un avance lento, cuando no a la inversa en la búsqueda de un mejor equilibrio entre economía, sociedad y medio ambiente en todo el mundo. Luego está la necesidad de cerrar la brecha entre estos dos puntos de vista, por lo que hay espacio para la construcción de acciones y políticas de desarrollo sostenible realmente viable. Este es el objetivo de este estudio teórico: proponer una perspectiva conceptual para el análisis y la toma sostenible, lo que permite un mayor acercamiento de estos dos puntos de vista. Desde un "mapa general", que localiza biocéntrica y antropocéntrica en campos opuestos, se inicia la construcción de una proposición analítica de un modelo conceptual de decisiones. La perspectiva de la ecología industrial se integra en la teoría de los stakeholders y la sostenibilidad 3-D del Mauerhofer (2008) para la construcción de esta propuesta, que está diseñada para reflejar las características intrínsecas del desarrollo sostenible y trabaja en la forma de un circuito cerrado, la retroalimentación. Este modelo responde al propósito de este ensayo teórico y su principal contribución. Se propone como un estudio de futuro: I. el desarrollo operativo y posterior aplicación de este modelo en los principales argumentos presentes biocéntrica y antropocéntrica en los foros de discusión diferentes; y 2. adaptarlo a industrias específicas.

\section{PALABRAS CLAVE}

Desarrollo sostenible; Modelo analítico y de decisión; Biocentrados; Antropocentrados; Ecología industrial. 


\section{REFERÊNCIAS}

BANERJEE, S. B. Who sustains whose development? Sustainable development and the reinvention of nature. Organization Studies, n. 24, p. I43-I80, 2003.

BUCHHOLZ, R. A.; ROSENTHAL, S. B. Integrating ethics all the way through: the issue of moral agency reconsidered. Journal of Business Ethics, v. 66, p. 233-239, 2006.

COHEN-ROSENTHAL, E. A walk on the human side of industrial ecology. American Behavioral Scientist, v. 44, n. 2, p. 245-264, 2000.

COMMONER, B. The closing circle. New York: Bantam Press, I972.

DETOMBE, D. Climate change: a complex societal process; analyzing a problem according to the Compram methodology. Social Change, v. 5, issue 3, p. 235-266, 2008.

EHRENFELD, J. R. Industrial ecology: paradigm shift or normal science. American Behavorial Scientist, v. 44, n. 2, p. 229-244, 2000.

ERKMAN, S. Industrial ecology: a historical view. Journal of Cleaner Production, v. 5, n. I-2, p. I-IO, I997.

FASSIN, Y. The stakeholder model refined. Journal of Business Ethics, v. 84, n. I, p. II3-I35, 2008.

FAUCHEUX, S.; FROGER, G.; NOEL, J. F. What forms of rationality for sustainable development? Journal of Socio-Economics, v. 24, issue I, p. 169-209, I995.

FREEMAN, R. E. Strategic management: a stakeholder approach. Boston: Pitman, I984.

FRIEDMAN, A. L.; MILES, S. Developing stakeholder theory. Journal of Management Studies, v. 39, n. I, p. I-2I, 2002.

GEORGESCU-ROEGEN, N. The entropy law and the economic process. Cambridge: Harvard University Press, I97I.

HOFFMAN, A. J. Linking social systems analysis to the industrial ecology framework. Organization \& Environment, v. I6, n. I, p. 66-86, 2003.

HOLMBERG, J.; SANDBROOK, R. Sustainable development: what is to be done? In: HOLMBERG, J.; SANDBROOK, R. Policies for a small planet. London: Earthscan, I992.

HOPWOOD, B.; MELLOR, M.; O’BRIEN, G. Sustainable development: mapping different approaches. Sustainable Development, v. I3, n. I, p. 38-52, 2005.

IPCC. Relatório do painel intergovernamental de mudança climática. In: CONFERÊNCIA LATINO-AMERICANA SOBRE MEIO AMBIENTE E RESPONSABILIDADE SOCIAL, 2007. Belo Horizonte, Minas Gerais. Instituto de Educação Tecnológica.

ISENMANN, R. Industrial ecology: shedding more light on its perspective of understanding nature as a model. Sustainable Development, v. II, n. 3, p. I43-158, 2003.

IYER-RANIGA, U.; TRELOAR, G. Forum: a context for participation in sustainable development. Environmental management, v. 26, n. 4, p. 349-36I, 2000.

JACKSON, T. Live better by consuming less? Journal of Industrial Ecology, v. 9, n. I-2, p. 19-36, 2005. JELINSKI, L. W.; GRAEDEL, T. E.; LAUDISE, R. A.; MCCALL, D. W.; PATEL, C. K. N. Industrial ecology: concepts and approaches. Proceedings of the National Academy of Sciences, v. 89, n. 3, p. 793-797, Feb. I992.

KAPLINSKY, R. Globalisation and unequalisation: what can be learned from value chain analysis? Journal of Development Studies, v. 37, n. 2, p. II7-I46, 2000. 
KARL-HENRIK, R. Tools and concepts for sustainable development, how do they relate to a general framework for sustainable development, and to each other? Journal of Cleaner Production, v. 8, n. 3, p. 243-254, 2000.

KERKHOF, M.; WIECZOREK, A. Learning and stakeholder participation in transition processes towards sustainability: methodological considerations. Technological Forecasting \& Social Change, v. 72, n. 6, p. 733-747, 2005 .

KORHONEN, J. Industrial ecology in the strategic sustainable development model: strategic applications of industrial ecology. Journal of Cleaner Production, v. I2, issues I2-IO, p. 809-823, 2004. KORTEN, D. When corporations rule the world. London: Earthscan, I996.

LIN, A. C. Virtual consumption: a second life for earth. Brigham Young University Law Review, v. 2008 , n. I, p. 47-II5, 2008.

LOVELOCK, L. Gaia: a new look at life on earth. Oxford: Oxford University Press, I975.

MAUERHOFER, V. 3-D sustainability: an approach for priority setting in situation of conflicting interests towards a sustainable development. Ecological Economics, v. 64, n. 3, p. 496-506, 2008.

MEBRATU, D. Sustainability and sustainable development historical and conceptual review. Environmental Impact Assessment Review, v. I8, n. 6, p. 493-520, I998.

MUNASINGHE, M. The sustainomics trans-disciplinary meta-framework for making development more sustainable: applications to energy issues. Sustainable Development, v. 5, n. I-2, p. 126-182, 2002. PEARCE, D. W.; BARBIER, E. B.; MARKANDYA, A. Blueprint for a green economy. London: Earthscan, I989.

ROBÈRT, K. H.; SCHMIDT-BLEEK, B.; ALOISI DE LARDEREL, J.; BASILE, G.; JANSEN, J. L.; KUEHR, R.; THOMAS, P. P.; SUZUKI, M.; HAWKEN, P.; WACKERNAGEL, M. Strategic sustainable development - selection, design and synergies of applied tools. Journal of Cleaner Production, v. Io, issue 3, p. 197-214, 2002.

ROBINSON, J. Squaring the circle? Some thoughts on the idea of sustainable development. Ecological Economics, v. 48, issue 4, p. 369-384, 2004.

ROSSI, P. Francis Bacon: from magic to science. Chicago: University of Chicago Press, I968.

SANNE, C. The consumption of our discontent. Business Strategy and the Environment, v. I4, issue 5, p. 3I5-323, 2005 .

SOLOW, R. M. Intergenerational equity and exhaustible resources. Review of Economic Studies (Symposium on the Economics of Exhaustible Resources), v. 4I, p. 29-46, I974.

WAAGE, S.; GEISER, K.; IRWIN, F.; WEISSMAN, A.; BERTOLUCCI, M.; FISK, P.; BASILE, G.; COWAN, S.; CAULEY, H.; MCPHERSON, A. Fitting together the building blocks for sustainability: a revised model for integrating ecological, social, and financial factors into business decision-making. Journal of Cleaner Production, v. I3, n. I2, p. I.I45-I.I63, 2005.

WORLD BUSINESS COUNCIL FOR SUSTAINABLE DEVELOPMENT. Cleaner production and eco-efficiency, complementary approaches to sustainable development. Geneva: World Business Council for Sustainable Development, I998.

WORLD COMMISSION ON ENVIRONMENT AND DEVELOPMENT. Our common future. Oxford: Oxford University Press, I987. 